\title{
Membangun Bisnis Berbahan Organik Masker Daun Kelor bagi Kelompok Majelis Taklim Kelurahan Lanna Kecamatan Parangloe Kabupaten Gowa
}

\author{
Tenriwaru*1, Nurwanah², Andi Aco Agus ${ }^{3}$
}

1,2,3Akuntansi, Fakultas Ekonomi dan Bisnis, Universitas Muslim Indonesia, Indonesia *e-mail: tenriwaru@umi.ac.id ${ }^{1}$, andinurwanah@umi.ac.id ${ }^{2}, \underline{\text { andi.aco.agus@unm.ac.id }}^{3}$

\begin{abstract}
Abstrak
Masker merupakan salah satu produk yang disukai terutama kaum wanita yang ingin kulitnya sehat dan bersinar. Walaupun produk ini akan menyebabkan pengeluaran ekstra bagi para wanita, tapi demi tampil maksimal biasanya mereka tidak segan mengucurkan banyak anggaran untuk memelihara kecantikan mereka. Disamping masker yang terbuat dari berbagai ramuan kimia, ada juga masker yang baik bagi kulit dan terbuat dari bahan organik yang mudah didapatkan dan berbahan murah yakni masker dari daun kelor. Kegiatan pengabdian ini bertujuan untuk memotivasi dan memberikan penyuluhan dalam mengembangkan potensi yang ada di desa untuk menjadi lahan bisnis bagi ibu-ibu yang tergabung dalam kelompok majelis taklim Kahirunnisa Desa Lanna Kecamatan Parangloe Kabupaten Gowa Sulawesi Selatan. Metode pelaksanaan kegiatan pengabdian yakni penyuluhan, pendampingan dan pelatihan. Kegiatan ini ini juga dilengkapi edukasi cara mengemas produk yang menarik perhatian konsumen, serta cara pamasaran via media sosial dan bagaimana menghitung harga pokok produk sehingga kelak mereka dapat menjadikan keterampilan membuat masker ini sebagai lahan untuk menambah penghasilan rumah tangga. Hasil pengabdian menunjukkan bahwa mitra sudah pandai mempraktekkan cara membuat masker, bisa menghtung harga pokok dan harga jual produk serta memgetahui pentingnya pengemasan untuk promosi produk dan memasarkan secara online.
\end{abstract}

Kata kunci: Daun Kelor, Harga Pokok Produk, Masker Organik, Pemasaran, Pengemasan

\begin{abstract}
Masks are one of the most popular products, especially for women who want healthy and glowing skin. Although this product will cause extra expenses for women, but in order to look optimal they usually do not hesitate to spend a lot of budget to maintain their beauty. In addition to masks made from various chemical ingredients, there are also masks that are good for the skin and made of organic materials that are easily available and inexpensive, namely masks from Moringa leaves. This service activity aims to motivate and provide counseling in developing the potential that exists in the village to become a business area for mothers who are members of the Kahirunnisa taklim assembly group, Lanna Village, Parangloe District, Gowa Regency, South Sulawesi. The method of implementing community service activities is counseling, mentoring and training. This activity is also equipped with education on how to package products that attract the attention of consumers, as well as how to market via social media and how to calculate the cost of products so that in the future they can use the skills to make masks as land to increase household income. The results of the service show that partners are good at practicing how to make masks, can calculate the cost of goods and the selling price of products and know the importance of packaging for product promotion and marketing online.
\end{abstract}

Keywords: Cost of Products, Marketing, Moringa Leaves, Organic Masks, Packaging

\section{PENDAHULUAN}

Kulit secara alami dapat mengalami penuaaan dini dan hal ini dapat disebabkan oleh sumber radikal bebas yang berasal dari lingkungan seperti polusi udara, sinar matahari, gesekan mekanik, suhu panas atau dingin dan reaksi oksidasi yang berlebihan yang dapat menyebabkan reaksi oksidatif seperti kerusakan atau kematian sel (Oktaviana dkk, 2012). Pada wanita, kulit wajah merupakan bagian yang sangat istimewa hingga banyak orang berlomba untuk mendapatkan kulit wajah yang terbaik. Kulit wajah yang sehat adalah kulit yang bersih, sehat, cerah, lembut, kenyal serta tidakkering (lembab).

Banyak cara yang bisa dilakukan untuk melakukan perawatan wajah. Berbagai cara bisa dipilih mulai dariperawatan dari dokter yang berbau kimia ataupun perawatan alami yang 
sederhana. Keduanya memiliki keuntungan dan kerugian masing masing. Perawatan wajah alami dapat dilakukan dengan berbagai cara. Namun apakah semua produk kecantikan itu cocok pada wajah semua orang.

Lagi pula alat kosmetik seperti alas bedak, bedak dan lainnya hanya bisa menutupi sementara saja. Padahal tujuan dari perawatan wajah adalah agar kita mendapatkan wajah yang sehat alami. Produk kecantikan itu juga tidak murah, harus mengeluarkan banyak uang untuk mendapatkannya apalagi untuk kualitas yang bagus, jika ada yang lebih murah namun dengan manfaat yang baik mengapa harus mahal.

Salah satu bahan alami yang dapat digunakan untuk perawatan kulit wajah adalah daun kelor. Masker organic dari daun kelor dapat menjadi alternatif kosmetik wajah yang bermanfaat bagi kesehatan kulit, murah harganya dan mudah didapatkan. Kelor memiliki nama latin Moringa Oleifera Lamk. Kelor adalah tanaman yang dapat tumbuh secara cepat dan mudah, tentunya tumbuh sepanjang tahun dan berumurpanjang. Daun kelor memiliki daun yang kecilkecil. Namun di balik daun kecilnya itu, kelor memiliki banyak manfaat bagi kesehatan dan kecantikan kulit. Tanaman daun kelor mengandung 46 senyawa antioksidan kuat atau senyawasenyawa dengan karakteristik antioksidan (Offor, 2014). Senyawa antioksidan ini dapat menetralisir radikal bebas yang merusak sel -sel dalam tubuh. Antioksidan dapat didefinisikan sebagai suatu zat yang dapat menghambat atau memperlambat proses oksidasi. Manfaat inilah yang digunakan oleh Sebagian orang sehingga mengambil kelor sebagai bahan pembuatan masker wajah.

Cara pembuatan masker organik dari daun kelor sangat sederhana hingga hampir semua orang dapat membuatnya. Daun kelor adalah tanaman yang apabila dikonsumsi tidakmemiliki efek samping, sangat baik digunakan untuk perawatan wajah. Kandungan yang terdapat pada daun kelor telah teruji untuk menghilangkan flek hitam apabila digunakan secara rutin (Muthukumar et.all, 2012).

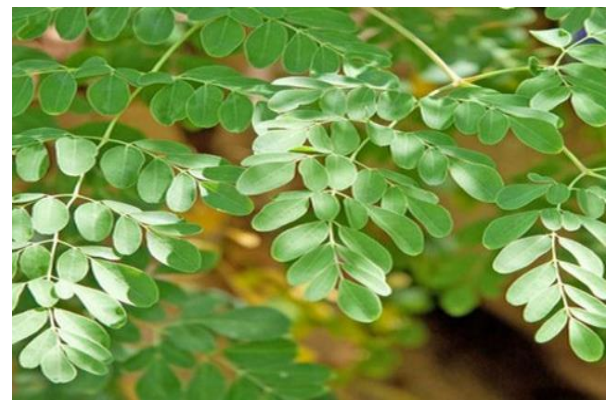

Gambar 1. Cara Penggunaan masker daun kelor

Pengabdian Kepada Masyarakat kali ini akan mengedukasi masyarakat untuk perawatan kecantikan berupa masker organik dari daun kelor. Masker organik terbuat dari bahan alami yang memiliki kandungan gizi yang baik untuk wajah. Masker organik memiliki banyak manfaat yang tentunya tidak kalah dari perawatan dokter kecantikan. Pengabdian kali ini kami akan lakukan pada kelompok Majelis Taklim di Kelurahan Lanna Kecamatan Parangloe Kabupaten Gowa. Desa Belabori lokasi mitra kami ini kaya akan tumbuhan batang kelor yang mudah didapatkan di beberapa sudut desa dan dimanfaatkan oleh warga setempat sebagai bahan baku pembuatan sayur yang dikonsumsi oleh mereka. Sehingga bahan baku pembuatan masker ini mudah didapatkan.

\section{METODE}

Adapun metode penyelesian masalah yang akan ditawarkan dalam kegiatan kali ini adalah sebagai berikut:

a. Melakukan penyuluhan untuk memberi pengetahuan dan pemahaman tentang pentingnya membudidayakan daun kelor bukan hanya sebatas bahan baku pembuatan sayur seperti yang mereka fahami selama ini. 
b. Melakukan penyuluhan tentang manfaat daun kelor baik untuk kesehatan tubuh maupun untuk kesehatan/kecantikan kulit.

c. Melakukan pelatihan dan pendampingan cara membuat masker dari daun kelor oleh tim pengabdi.

d. Mengajarkan cara mengemas, memasarkan serta menghitung harga pokok produk (berwirausaha dengan masker daun kelor).

\section{HASIL DAN PEMBAHASAN}

Untuk memberdayakan kaum perempuan di pedesaan perempuan memiliki keterbatasan dalam menjalankan aktivitasnya. keterbatasan tersebut seperti rendahnya pendidikan, keterampilan, sedikitnya kesempatan kerja, dan juga hambatan ideologis perempuan yang terkait rumah tangga. Selain itu perempuan juga dihadapkan pada kendala tertentu yang dikenal dengan istilah "tripple burden of women", yaitu perempuan harus melakukan fungsi reproduksi, produksi dan fungsi sosial secara bersamaan di masyarakat. Hal tersebut menyebabkan kesempatan perempuan untuk memanfaatkan peluang ekonomi yang ada menjadi sangat terbatas (Aditiawati : 2016)

Di bidang ekonomi, pemberdayaan perempuan lebih banyak ditekankan untuk meningkatkan kemampuan dalam mengelola usaha, khususnya dalam hal ini adalah home industry. Sebagai mana pemberdayaan tersebut di realisasikan melalui Usaha Mikro Kecil Menengah (UMKM). Terkait dengan pemberdayaan perempuan dalam home industry, hal yang perlu dilakukan adalah penciptaan iklim yang kondusif yang mampu menstimulus pengembangan diri kaum perempuan.

Pengembangan kompetensi dan kapasitas kaum perempuan bisa dilakukan dalam lingkup terkecil seperti dalam kelompok majelis taklim seperti yang kami lakukan dengan memberikan materi mengenai pentingnya kaum perempuan berdaya secara pendidikan dan ekonomi. Pembuatan masker daun kelor bisa menjadi salah sarana berwirausaha karena cara membuatnya mudah dan alat yang dipergunakan untuk memproduksi masker ini juga masih dapat dikerjakan dengan alat yang ada di dapur mereka.

Adapun proses pembuatan masker ini adalah:

a. Rendam beras ketan selama semalam yang berfungsi untuk membersihkan kotoran pada beras dan membuat beras lebih lunak saat proses penumbukkan

b. Sediakan daun kelor, bersihkan dari batangnya kemudian cuci daun kelor sampai bersih, kemudian jemur daun kelor sampai kering

c. setelah itu sediaan bahan bengkoang, temulawak, dan biji pinang, lalu setelah beras di rendam semalam, tumbu beras bersama bahan lainnya serta kelor yang telah dijemur sampai testurnya halus kemudian masukan minyak zaitun dengan ukuran $1 / 2$ botol minyak zaitun untuk ukuran 1 liter beras yang dihaluskan.

d. Setelah semua bahan ditumbuk dan halus, jemur semua bahan selama 3-4 hari sampai kondisi bahan kering, usahakan untuk bahan kondisi benar benar kering agar bisa bertahan dan tidak berjamur selama beberapa bulan

e. Untuk proses terakhir, setelah bahan selesai dijemur kemudian saring bahan atau ayak bahan agar menjadi serbuk halus

f. Setelah menjadi serbuk halus uji bahan produk aman untuk digunakan dengan metode test laboratorium atau test pemakaian pada beberapa kulit wajah

g. Jika proses tester berhasil dan tidak terjadi alergi pada kulit, maka produk siap untuk dipasarkan atau diperjual belikan

Dari program pengabdian ini kami melihat bahwa mitra kami mampu membuat masker melalui pendampingan yang kami lakukan dan begitu pula materi lainnya yang kami berikan dapat difahami oleh mitra pengabdian ini. Hasil dari program pengabdian kami evaluasi melalui kunjungan langsung ke tempat mitra dan melihat aktivitas yang terkait dengan materi yang kami berikan kepada mereka. Kami juga melakukan pre tes dan post test berkaitan dengan materi pengabdian dan hasilnya kami evaluasi untuk melihat pemahaman dan penerimaan 
mereka atas apa yang telah kami ajarkan mengenai keterampilan mereka membuat masker dan cara mengemas, memasarkan, dan menghitung harga pokok produk.

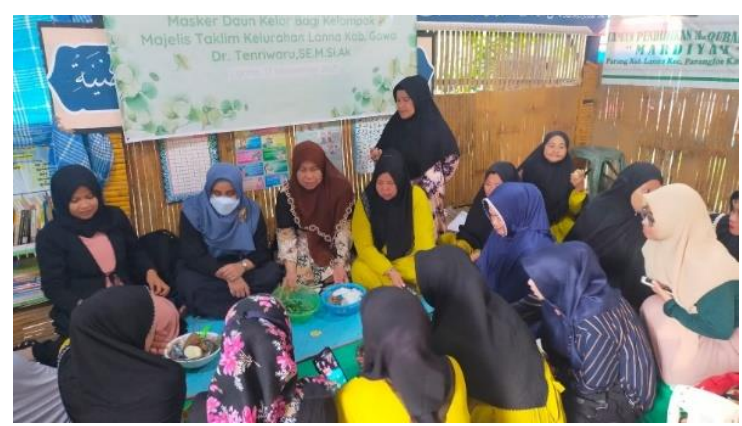

Gambar 2. Proses Pembuatan Masker

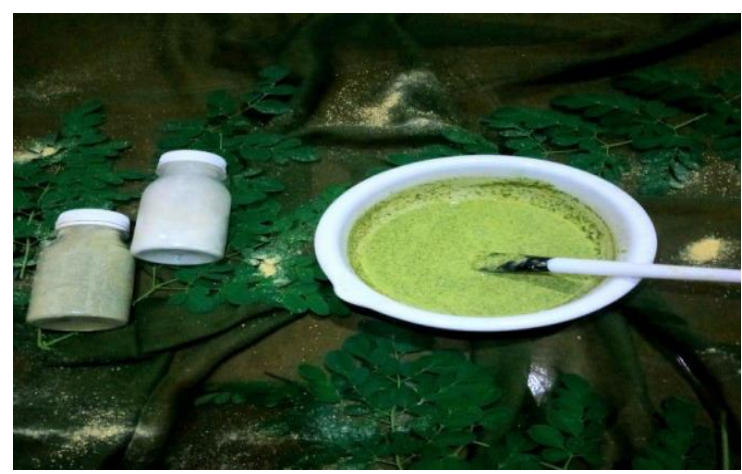

Gambar 3. Produk masker

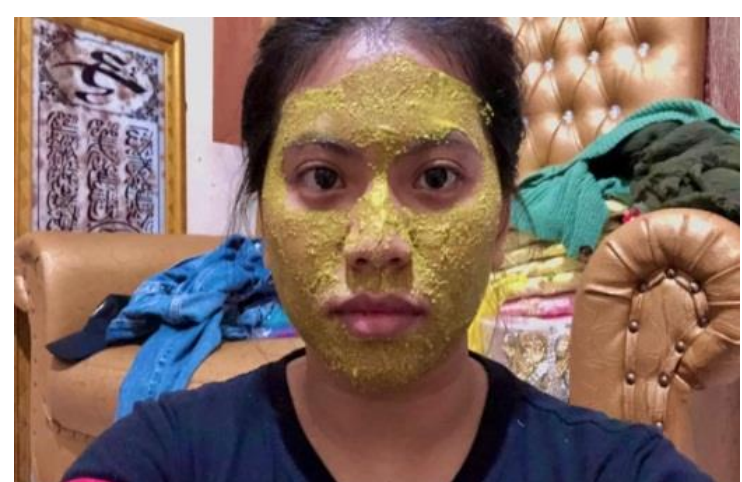

Gambar 4. Praktek penggunaan masker

Pre tes kami lakukan dengan mengedarkan kuesioner kepada mitra mengenai pemahaman mereka tentang manfaat kelor yang mereka ketahui serta bagaimana membangun usaha dengan keterampilan yang mereka miliki. Disitu juga kami menguji pengetahuan mereka tentang harga pokok, harga jual dan bagaiaman memasarkan produk secara online. Berangkat dari hasil pre tes inilah kemudian kami melakukan penyululuhan dan pendampingan sesuai tujuan pengabdian. Setelah beberapa kali mereka berlatih didampingi tim pengabdi pada akhirnya mereka mampu membuat masker daun kelor beserta bagaimana cara menghitung harga pokok produk dan menetukan harga jualnya. Setelah itu kami melakukan pos tes untuk melihat peningkatan pengetahuan dan keterampilan mitra yang berkaitan dengan tujuan pengabdian dan kami evaluasi dengan memberikan mereka bahan pembuatan masker dan melihat langsung cara mereka memproduksi masker ini.

Apabila masih ada kelemahan yang kami temukan maka kami akan melakukan pendampingan ulang hingga mitra betul-betul memahami cara membuat masker ini dan mampu menerapkan pengetahuan ini untuk berwirausaha yang pada akhirnya bisa membantu meningkatkan pendapatan keluarga. 


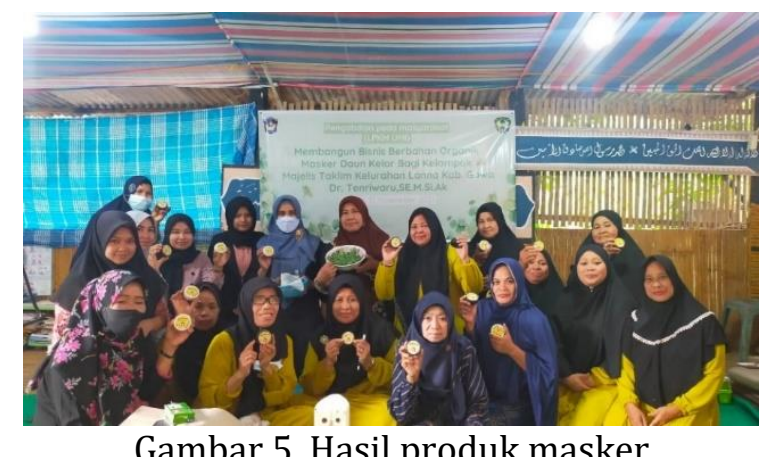

Dari hasil diskusi dengan anggota mitra mereka berterimakasih karena telah dilibatkan dalam kegiatan pengabdian ini. Ada beberapa keluhan yang mereka sampaikan kepada kami berkaitan dengan kondisi objektif yang mereka hadapi yakni rendahnya tingkat Pendidikan yang dimilki oleh para anggota yang rata-rata hanya tamatan Sekolah Menengah Atas karena keterbatasn ekonomi yang menyebabkan mereka tidak memiliki biaya untuk melanjutkan Pendidikan. Hambatan lainnya berkaian dengan pendidikan yang dimiliki adalah terbatasnya akses informasi yang dimilki karena walaupun rata-rata memilki gadget tetapi mereka belum mampu emanfaatkan secara maksimal gadget itu untuk menambah kapasitas pengetahuan dan keterampilan yang dimiliki. Contohnya seperti pemanfaatan bahan organik yang ada di lingkungan sekitar mereka yang belum mampu dimanfaatkan secara maksimal karena terbatasnya pengetahuan yang mereka miliki. Selain itu mereka juga belum memiliki rencana pengembangan bisnis karena belum pernah mendapatkan penyuluhan berkaitan dengan hal ini. Kendala lain yang dihadapi adalah belum adanya motivasi yang kuat dan berkesinambungan berkaitan dengan membangun bisnis dari potensi yang ada di sekitar lingkungan mereka karena belum adanya pemahaman tentang potensi wirausaha bagi ibu rumah tangga.

\section{KESIMPULAN}

Daun kelor sebagai bahan lauk yang biasa dikonsumsi sebagai sayur memiliki banyak kandungan gizi dan berguna bagi kecantikan kulit. Potensi inilah yang kami kenalkan kepada kelompok mitra untuk membuat masker berbahan organik dari daun kelor. Metode penyuluhan dan pendampingan yang kami lakukan dalam pengadian terlihat bahwa kaum ibu-ibu memilki semangat untuk mengembangkan pengetahuan dan keterampilan mengolah daun kelor menjadi masker.

Hasil dari pengabdian ini menunjukkan terjadi peningkatan pengetahuan dan pemahaman mengolah daun kelor menjadi masker dan menjadikan keterampilan ini sebagai modal awal untuk berwirausaha. Tentunya hal ini akan mendorong peningkatan pendapatan keluarga dan mengatasi pengangguran dengan memaksimalkan potensi yang ada pada diri mitra. Pemberdayaan kaum perempuan sebagai tolak ukur keberhasilan keluarga akan tercapai.

\section{DAFTAR PUSTAKA}

Aditiawati, Pingkan dkk. 2016. Pengembangan Potensi Lokal di Desa Panawangan Sebagai Model Desa Vokasi Dalam Pemberdayaan Masyarakat dan 124 Peningkatan Ketahanan Pangan Nasional. Bandung: Institut Teknologi Bandung

Muthukumar, M., Naveena, B. M., Vaithiyanathan, S., Sen, A. R., \& Sureshkumar, K. (2012). Effect of incorporation of Moringa oleifera leaves extract on quality of ground pork patties. Journal of Food Science and Technology http://dx.doi.org/10.1007/s13197-012-0831-8

Offor IF, Ehiri RC, Njoku CN. 2014. Roximate Nutritional Analysis and Heavy Metal Composition of Dried Moringa Oleifera Leaves from Oshiri Onicha L.G.A, Ebonyi State, Nigeria. IOSR Journal of Environmental Science, Toxicology and Food Technology. 1(1): 57-62. 
Oktaviana KT, Indra MR, Ratnawati R. 2012. Pengaruh Ekstrak Metanol Daun Kelor (Moringa Oleifera) Terhadap Penghambatan Aktivasi NF-KB Pada Hepar Tikus Wistar Model Hepatocellular Carcinoma (HCC) Yang Diinduksi DMBA (7,12 Dimethybenz( $\alpha)$ Anthracene) [Skripsi]. Malang: Universitas Brawijaya. 